\title{
A IMPORTÂNCIA DO FEEDBACK COMO FERRAMENTA PEDAGÓGICA NA EDUCAÇÃO À DISTÂNCIA
}

Carmem Silvia Lima Fluminhan ${ }^{1}$, Alba Regina Azevedo Arana ${ }^{2,3}$, Antonio Fluminhan ${ }^{3}$

${ }^{1}$ Discente do Curso de Especialização em Avaliação do Ensino e da Aprendizagem EAD. ${ }^{2}$ Docente do Curso de Especialização em Avaliação do Ensino e da Aprendizagem EAD. ${ }^{3}$ Docente do Programa de Mestrado em Meio Ambiente e Desenvolvimento Regional- MMADRE. E-mail: carmem.slima@hotmail.com

\section{RESUMO}

O presente trabalho teve por objetivo descrever a importância da utilização de feedback como ferramenta pedagógica na educação a distância. Foram apresentados diferentes conceitos de feedback, bem como descrições detalhadas da sua importância para o processo de ensino e aprendizagem e o impacto que estes podem causar ao aprendiz. Discutiu-se o feedback como ato de comunicação, o papel do feedback na educação à distancia e a função do feedback entre os pares. Ao final, com base nos resultados apresentados na extensa literatura especializada, foram propostas sugestões práticas de feedback com a finalidade de auxiliar docentes na execução desta importante ferramenta de comunicação, correção e motivação.

Palavras-chave: feedback , ferramenta pedagógica, educação a distância.

\section{INTRODUÇÃO}

Em todos os aspectos da atividade humana, em todos os momentos em que há comunicação, é necessário que haja um feedback entre o emissor e o receptor da informação (ou retroalimentação, na tradução livre para o idioma português), seja para confirmar o que foi emitido, seja para orientar novas práticas ou para corrigir o que já foi dito ou executado.

Observa-se, entretanto, que o feedback é um importante recurso de comunicação, porém tem sido negligenciado por professores que, por falta de tempo em sala de aula, por excesso de trabalho, por desconhecimento de sua eficácia ou por inabilidade em tratá-lo como um ato de orientação, de acompanhamento e de avaliação, simplesmente se omitem em praticá-lo de forma regular e consistente.

Apesar do feedback ser fundamental para o sucesso do processo de ensino e aprendizagem, ainda não existem muitas pesquisas sobre o assunto, em especial no Brasil, que venham a estimular e fomentar o aprofundamento das possibilidades de acompanhamento, orientação e correção ofertados por esta importante ferramenta pedagógica.

\section{OBJETIVOS}

A presente pesquisa abordou a utilização do feedback como ferramenta avaliativa e motivadora no processo de ensino e aprendizagem em ensino à distância. Objetiva-se contribuir 
para que professores adotem mecanismos de feedback, através das sugestões práticas para que esses agentes estejam mais bem preparados para utilizar esta ferramenta pedagógica de forma corretiva, motivadora e eficaz no processo de ensino e de aprendizagem na educação a distância.

\section{MATERIAIS E MÉTODOS}

Para a realização da presente pesquisa foram consultadas publicações na literatura especializada e que estão disponíveis em bancos de dados indexados internacionalmente. As pesquisas bibliográficas permitiram reunir um significativo número de publicações, que envolveram: livros, dissertações e teses de cursos de pós-graduação stricto-sensu, artigos completos publicados em periódicos nacionais e internacionais, monografias de especialização e apresentações de palestras com acesso livre através da internet. Constatou-se que há um reduzido número de publicações realizadas no Brasil e, deste modo, procurou-se dar um enfoque analítico à pesquisa, respeitando-se as diferenças existentes em cada um dos estudos publicados, em relação a: grau de conhecimento dos docentes e coordenações de cursos, níveis de escolaridade dos discentes, utilização de recursos de tecnologia de informação, entre outros.

\section{RESULTADOS E DISCUSSÃO}

\section{A Ferramenta Feedback}

O termo feedback foi originalmente cunhado na área de biologia para referir-se ao processo de resposta que o organismo realiza após interagir em seu ambiente (SANTOS, 2012). Entretanto, atualmente esse termo é amplamente utilizado em diversas áreas, tais como informática e educação, porém seu sentido inicial não foi perdido.

Estudos realizados por Mason e Bruning (2003) apontam que foi somente durante o predomínio do behaviorismo que o termo feedback passou a ser usado na área de ensino e aprendizagem. Ainda segundo os autores, do ponto de vista behaviorista, o feedback não exercia uma função corretiva, não era considerado uma ferramenta que pudesse conduzir o aluno ao caminho correto, à reflexão de seu desempenho, e, desta forma, estava limitado em relação ao processo de ensino e aprendizagem.

Com o cognitivismo, nos anos 1970 e 1980, o feedback adquiriu uma nova função. O erro deixou de ser simplesmente descartado e passou a ser uma fonte de referência sobre os processos cognitivos do aluno, e desta forma, tornou-se parte integrante do processo de ensino e aprendizagem. Desde então, o feedback tem como objetivo auxiliar o aluno a identificar suas 
falhas e melhorar seu desempenho, buscar maneiras de corrigir o que não está correto e desenvolver o potencial desejado (MASON e BRUNING, 2003).

Diversos pesquisadores da área de educação propuseram diferentes definições para o termo feedback no contexto de ensino e aprendizagem. Para Vrasidas e Mclsaac (1999), o feedback é o conjunto de respostas que o professor fornece ao aluno sobre a correção das diferentes atividades propostas, como, por exemplo, deveres de casa, trabalhos extra classe e contribuições em sala de aula. Entretanto, segundo os autores, o feedback ainda encontra-se restrito à correção de tarefas e às contribuições dos alunos. Mason e Bruning (2003) definem feedback como qualquer ato emitido em resposta a ação do aluno.

Para Shute (2007), o feedback deve assumir um papel formativo no contexto educacional. A autora define como "informação comunicada ao aprendiz com o objetivo de modificar seu pensamento ou comportamento para promover a aprendizagem". Ainda, segundo esta autora, "o principal objetivo do feedback formativo é aumentar o conhecimento, as habilidades e a compreensão do aluno em relação a um conteúdo".

No contexto on-line, Shute (2007) considera que o feedback formativo é toda informação oferecida ao aluno, por meio de uma mensagem, display, vídeo, áudio, e outros meios, em resposta a uma ação do aluno (contribuições, tarefas dirigidas, questionamentos etc.) que tenha como alvo moldar sua percepção, ação e cognição, para facilitar sua aprendizagem e favorecer seu desenvolvimento.

De acordo com Paiva (2003), feedback é a "reação à presença ou ausência de alguma ação com o objetivo de avaliar ou pedir avaliação sobre o desempenho no processo de ensinoaprendizagem e de refletir sobre a interação de forma a estimulá-la, controlá-la ou avaliá-la". Sua definição é bem mais abrangente do que as anteriores, pois considera que o feedback pode ser fornecido não apenas pelo professor, mas também por um colega ou até por outro agente alheio ao processo de aprendizagem, e, por esta razão, a autora dispensa o uso de expressões como professor, aprendiz, aluno e computador.

\section{O Papel do Feedback na Educação a Distância}

Em ambientes educacionais presenciais, professores e alunos estão em constante interação e contam com elementos verbais e não-verbais. Em uma abordagem sobre o assunto, Paiva (2003) descreve que em tais ambientes os alunos observam a atuação do professor e percebem seus movimentos, tais como, expressões faciais, gestos, acenos com a cabeça etc. No entanto, segundo 
o mesmo autor, em ambientes de ensino virtuais percebe-se que muito frequentemente os alunos sentem-se isolados, desatendidos, desmotivados e acabam abandonando o curso. Pode-se afirmar, portanto, que em nenhum outro contexto o feedback é mais ansiosamente aguardado quanto no ensino a distância.

Kasprzak (2005) afirma que o feedback é um recurso fundamental na modalidade educacional on-line, pois ele torna o professor mais presente e contribui para a motivação do aluno, amparando-o em seus questionamentos, superando o isolamento e direcionando o seu caminhar. O autor descreve o ambiente on-line como um espaço "frio", "impessoal" e "distante" para aqueles que não estão habituados a tais contextos ou que até mesmo para os que encontram dificuldades com o uso da tecnologia para a aprendizagem. Em contrapartida, o aluno pode considerar um feedback negativo quando o professor silencia-se, levando-o à desmotivação e ao consequente abandono do curso (PAIVA, 2003).

Vrasidas e Mclsaac (1999) afirmam que o feedback é um importante recurso que influencia diretamente a qualidade e a intensidade da interação entres os agentes educacionais participantes de cursos on-line. Os autores realizaram pesquisas que investigaram a interação em cursos on-line e concluíram que: a) os alunos valorizavam o feedback individualizado oferecido tanto pelo professor quanto pelos seus pares; b) a falta de feedback imediato pode prejudicar a dinâmica da participação dos alunos e gerar desmotivação; c) enquanto os alunos não recebiam feedback, os mesmos se abstinham em prosseguir postando e contribuindo para com o tema proposto; e d) é essencial oferecer feedback para que os alunos se sintam assistidos e para motivar a interação entre os alunos.

Segundo White (2003), o feedback é muito valorizado pelo aluno de ensino a distância e é o alicerce do diálogo entre o professor e o aprendiz, provocando motivação, encorajamento e suporte para a realização das tarefas.

De acordo com Cardoso (2011), o conteúdo do feedback em cursos on-line difere quanto aos tipos de informação/objetivos e ao nível de complexidade. Quanto aos tipos de informação/objetivos, a autora afirma que o feedback pode ser de reconhecimento, motivacional/interacional, tecnológico ou informativo/avaliativo. Segundo Kielty (2004), o feedback de reconhecimento é aquele em que o professor confirma ao aluno a ocorrência de um evento. Ou seja, o professor retorna ao aluno para confirmar o recebimento de uma tarefa, por exemplo. Paiva (2003) descreve o feedback motivacional/interacional como aquele relacionado às emoções, em que o professor interage com o aluno procurando motivá-lo, evitando que ele se 
sinta isolado e, consequentemente, desista do curso. Ainda segundo Paiva (2003), "este tipo de feedback é muito importante, visto que a aprendizagem se realiza por meio de interações sociais entre alunos e professores".

Pyke e Sherlock (2010) afirmam que o feedback tecnológico está relacionado às informações acerca do uso do software adotado pelo curso. Por fim, Mason e Bruning (2003) e Paiva (2003) apontam que o feedback informativo/avaliativo oferece informação ou "algum tipo de avaliação do aluno".

Como descrito por Cardoso (2011), quanto ao nível de complexidade existente em seu conteúdo, o feedback pode ser complexo ou não-complexo. Segundo Shute (2007), feedbacks do tipo complexo são aquelas mensagens extensas ou de difícil compreensão. $\mathrm{O}$ autor argumenta que tais feedbacks podem levar os alunos a perderem o foco, podem não comunicar o que se deseja e se revelarem ineficaz. Em contrapartida, o feedback do tipo não-complexo é claro, assertivo e de fácil entendimento.

Kielty (2004) afirma que a extensa carga de trabalho dos instrutores dificulta o rápido retorno que os alunos esperam. Estudos realizados por Ikpa (2000) revelam que a expectativa dos alunos é de que os tutores estejam disponíveis para oferecerem feedback às suas postagens, exames, questionamentos e trabalhos enviados 24 horas por dia, 7 dias por semana. Em outras palavras, os alunos esperam por respostas instantâneas. Quando os alunos necessitam de assistência, esperar por um retorno via e-mail por 24 a 48 horas, ou aguardar por um período de 1 a 2 semanas por um feedback a um trabalho enviado é, para muitos alunos, inaceitável (KIELTY, 2004). Alunos de educação a distância, segundo Zvacek (2003), consideram que a espera por um feedback é uma das maiores desvantagens deste tipo de curso. Por outro lado, pesquisas realizadas por Vrasidas e Mclsaac (1999) apontam que a aprendizagem ocorre mais rapidamente e com maior eficácia quando os alunos recebem feedback imediato e contínuo. Portanto, para evitar possíveis insatisfações e frustrações, Ikpa (2000) defende que o aluno seja informado logo no início da unidade de ensino a respeito dos prazos que os instrutores terão para responder às perguntas e corrigir os trabalhos e as provas. Ainda segundo o autor, tal providência reduz sensivelmente o nível de ansiedade dos alunos.

Ressalta-se, ainda, que a promoção excessiva de feedback deve ser evitada, uma vez que tal excesso pode produzir um efeito contrário. Neste caso, o feedback torna-se "cansativo" e até mesmo desmotivador, já que o aluno pode considerá-lo irreal e desconfiar de sua veracidade e intencionalidade. Além disso, o feedback em excesso acaba por induzir as novas contribuições, 
influenciando o debate e restringindo as postagens de ideias contrárias às do senso comum do grupo.

Thac Sĩ (2008) afirma que graças ao desenvolvimento tecnológico, várias universidades e instituições de ensino têm adotado esta ferramenta pedagógica on-line. Teoricamente, o feedback entre os pares é um tipo de aprendizagem colaborativa em que os alunos aprendem a analisar e, em seguida, oferecem um feedback construtivo aos seus pares em atividades escritas (TRAHASCH, 2004). Thac Sĩ (2008) afirma que, a fim de economizar tempo em sala de aula e de promover um ambiente menos estressante, muitos professores têm usado o "Sistema On-line de Correção Entre os Pares" (OPAS, sigla do inglês para 'Online Peer Assesment System').

\section{CONCLUSÕES}

Devem existir critérios claros e bem definidos para o oferecimento de feedback aos alunos. Os professores sentem-se desmotivados em prover feedback avaliativo e motivacional aos seus alunos por diversas razões, entre elas: pela falta de conhecimento acerca dos benefícios de sua prática, por excesso de trabalho, em uma jornada diária cansativa e extensa, pela falta de comprometimento por parte dos alunos em seguirem as orientações contidas nos feedbacks, e por não receberem incentivo por parte das respectivas coordenações pedagógicas e das direções de ensino.

É fundamental que o aluno conheça os resultados de suas práticas educacionais e de seu desempenho. Afim de que haja uma avaliação transparente e justa, o professor deve definir claramente o que pretende observar ao oferecer feedback, pois somente com a clareza dos seus critérios é que professores e alunos poderão se beneficiar desta prática pedagógica e favorecer o aprimoramento do ensino e da aprendizagem. Discutir os critérios de avaliação previamente de forma esclarecedora resulta em um bom relacionamento entre o professor e o aluno.

Com base na literatura especializada, algumas sugestões práticas para o professor de língua estrangeira na adoção de mecanismos de feedback são: a) forneça o feedback com a maior rapidez possível ou dentro do prazo estipulado pela instituição de ensino; b) sempre abra espaço para que os alunos possam questionar, fazer sugestões e criticar tanto a ação pedagógica, como a avaliação promovida pelo professor; c) realize o feedback do tipo conferência sempre que possível; d) procure diversificar as formas de fornecer o retorno aos alunos; e) após prover o feedback aguarde um tempo suficiente para que o aluno possa processar o que lhe foi dito, reformular sua resposta e produzir um resultado mais coerente e acertado; f) programe atividades 
para que os alunos realizem a correção e avaliação entre os pares, o chamado "peer feedback"; g) utilize um modelo de avaliação que seja honesto ao corrigir as falhas e equívocos apresentados pelos alunos, mas que seja, acima de tudo, uma ferramenta que valorize os aspectos positivos observados durante a realização da tarefa; h) procure equilibrar a frequência de feedback ofertado. $\mathrm{O}$ excesso de feedback pode gerar efeitos negativos à aprendizagem.

A forma, a estratégia e a frequência na promoção de feedback utilizadas pelo professor podem, portanto, ser decisivas para o sucesso do desenvolvimento do ensino e da aprendizagem.

\section{REFERÊNCIAS}

CARDOSO, A. C. S. Feedback em contextos de ensino-aprendizagem on-line. Feedback in distance education. Linguagens e Diálogos, v. 2, n. 2, p. 17-34, 2011.

IKPA, V. (2000). Strategies for developing and managing an online course. ITC Featured Essay. Disponível em: http://www.itcnetwork.org/ITCmembersOnly/Essay12200.pdf (Acesso em: 05/04/ 2013).

KASPRZAK, J. Providing Students Feedback in Distance Education Courses. An Online Learning Magazine for UMUC Faculty, 2005. Disponível em: http://deoracle.org/on-linepedagogy/assessment-feedback-rubrics/providing-student-feedback-in-distance-educationcourses (Acesso em: 28/03/2013).

KIELTY, L. Feedback in Distance Learning: Do students perceptions of corrective feedback affect retention in Distance Learning? Theses and Dissertations. Paper 1114. University of South Florida, 2004. Disponível em: http://scholarcommons.usf.edu/etd/1114 (Acesso em: 28/042013).

MASON, B. e BRUNING, R. Providing Feedback in Computer-based Instruction: What the Research tells us, 2003. Disponível em: http://dwb.unl.edu/Edit/MB/MasonBruning.html (Acesso em: 15/03/2013).

PAIVA, V. L. M. O. Feedback em Ambiente Virtual. In: LEFFA, V. (Org.) Interação na aprendizagem das línguas. Pelotas: EDUCAT, 2003. Disponível em: www.veramenezes.com/ feedback.htm (Acesso em: 28/03/2013).

PYKE, J. e SHERLOCK, J. A closer look at instructor-student feedback on-line: a case study analysis of the types and frequency. MERLOT Journal of Online Learning and teaching, vol. 6, no. 1, March 2010. Disponível em: http://jolt.merlot.org/vol6no1/pyke 0310.pdf (Acesso em: 02/04/2013).

SANTOS, L. (2012). Introdução à fisiologia: homeostase e sistemas alostáticos. Disponível em: http://heldermauad.com/graduacao/PDF\%20FISIO/GERAL/2012/

2012 LEO Introducao fisiologia homeostase PSICO.pdf (Acesso em: 09/04/2013).

SHUTE, V. Focus on formative feedback. ETS Research e Development. Princeton, NJ, March 2007. Disponível em: www.ets.org/Media/Research/pdf/RR-07-11.pdf (Acesso em: 13/05/2013). 
THAC SĨ, L.V. (2008). The impact of online peer feedback on EFL learner's motivation in writing performance: a case study at Can Tho University. Disponível em: http://www.ctu.edu.vn/guidelines/scientific/thesis/part1/Examples/LuanVanCaoHocHMHIEN\%20 K11DHCT.pdf (Acesso em: 04/04/2013).

TRAHASH, S. (2004). From peer assessment towards collaborative learning. 34thASEE/IEEE Frontiers in Education Conference. Disponível em: http://fie.engrng.pitt.edu/fie2004/ papers/1256.pdf (Acesso em: 04/04/2013).

VRASIDAS, C. e McISAAC, M.S. Factors Influencing Interaction in an Online Course. American Journal of Distance Education, 1999. http://dx.doi.org/10.1080/08923649909527033

WHITE, C. Language Learning in Distance Education. Cambridge: Cambridge University Press, 2003. http://dx.doi.org/10.1017/CBO9780511667312

ZVACEK, S. M. What's my grade? Assessing Learner Progress. [collection of essays]. Disponível em: http://fcae.nova.edu/pet/simonson/monograph.pdf (Acesso em: 05/04/2013). 